\section{Structural survey}

\section{Janet $M$. Thornton}

Introduction to Proteins and Protein Engineering. By Barry Robson and Jean Garnier. Elsevier: 1986. Pp. 699. Dfl.475, $\$ 190$.

IRONICALLY it is the explosive growth in DNA sequence data and technology which has emphasized the urgent need for a deeper understanding of proteins and especially the relationship between sequence, structure and function. It has awakened in many experimental biochemists, immunologists and molecular biologists an interest in protein structure, and has generated the requirement for at least a minimal understanding as a basis for rational design of protein engineering experiments. In this context a new book on proteins and protein engineering is both timely and useful.

The text covers an enormous range of topics, from basic protein biochemistry, through gene manipulation to drug and vaccine design, and inevitably the emphasis reflects the interests of the authors. Robson and Garnier set out to produce a non-specialist text, comprehensible to a scientist of any discipline, which was written to be read rather than 'referred to'. This is a difficult task and underlies the book's strengths and weaknesses.

The book comprises three distinct parts. The first half is introductory, covering protein structure and function and gene manipulation. As well as the conventional descriptions of protein secondary and tertiary structure, there is the standard case study of a protein (lysozyme) and a chapter devoted to both metalloproteins and gene manipulation. Although these topics are now included in many texts they are well presented here, and some interesting historical perspectives are included. The central section describes current methods of structure prediction and constitutes almost one third of the book. Although this section begins at the general level, it becomes much more detailed and can only be described as specialist. Inevitably the authors draw heavily from their own research work, and it is sometimes difficult to extract the general principles from the detail. While it is appropriate for the scientist intent on structure prediction, it may be too difficult for the casual reader to follow. The final two chapters, forming the third part, concentrate on the background and methods involved in drug and vaccine design. These areas are at the forefront of current applied research and have immense importance in medicine. The authors have attempted to survey recent advances including, for example,

calculations, which has its own appendix.

For the most part, the authors have succeeded in their objective by making this a book to be read, rather than a reference text. Overall it provides an up-to-date description of proteins and the modern techniques of protein engineering and successfully demonstrates the potential range of applications of these techniques to modern medicine. Although too long for most undergraduate courses, it would be a useful addition to any research library and for any individual scientist who seriously wishes to explore for the first time the world of proteins and protein engineering.

Janet $M$. Thornton is a lecturer in the crystallography department at Birkbeck College, University of London, Malet Street, London University of Lond
$W C 1 E 7 H X, U K$.

\section{Tracts of wisdom}

\section{T. Scratcherd}

Physiology of the Gastrointestinal Tract, 2nd Edn. Editor-in-chief Leonard R. Johnson. Raven: 1987. Two volumes, pp. $1,876 . \$ 250$.

THIs second edition of a work already established as a leading reference manual on gastrointestinal physiology is most welcome. There can be few books which can claim to be as comprehensive, with the possible exception of the American Physiological Society's Handbook on the Alimentary Canal, alas now out of date. It should be in all libraries, not only in those of universities and research institutes but also in the personal libraries of scientists and clinicians with a specialist interest in gastroenterology. In some ways the title is a misnomer: although most of the two volumes are concerned with physiology, pathophysiological topics, from peptic ulcers to parasites, are briefly considered.

This is a book for experts. In most chapters, evidence for mechanisms is precisely stated, citing the appropriate papers with a critical evaluation of the evidence presented. As a source of information it would be inappropriate for, say, a lecturer whose expertise is not in gastroenterology to use it to prepare a lecture. For example, should he wish to know the effect of the sympathetic nerves and adrenergic agonists on the pancreas, he would be faced with a plethora of apparently contradictory evidence, all correctly reported, and he would have to rely on the final conclusion that "No clear pattern emerges from the large number of studies on adrenergic regulation of exocrine pancreatic secretion": yet, clearly, adrenergic mechanisms can be demonstrated and common mechanisms are present.

In some, but not in all chapters, there is a lack of historical perspective with little account taken of the development of ideas. Perhaps this is a price that has to be paid so that work published as recently as 1986 can be critically reviewed in a limited space. Hence this book does not make classical works, such as those by Babkin, Alvarez and Gregory, redundant.

The contributors have dealt with some of the most controversial topics in this field in an exemplary way: particularly useful are the detailed critical analyses of the current views of the inhibition of gastric secretion, the physiology of the 'enterogastrones' and the role of the cephalic phase in the control of exocrine pancreatic function.

In addition to the traditional subdivisions of motility, secretion, absorption and blood flow, the book covers functional morphology, immunology, intestinal flora, parasites and various aspects of pharmacology of the gut. Two rapidly expanding areas of knowledge which are in general poorly understood, the enteric nervous system and the regulatory peptides, are presented in a quite masterly fashion. Since the isolation and sequencing of gastrin and secretin, the gastrointestinal hormonal profile has proliferated to such an extent that most workers outside the field are left in bewilderment as to their function and how they fit into integrative control mechanisms. Dockray and Walsh have, to my mind, removed some of the barriers to understanding and made sense out of a puzzling morass.

This edition is completely revised and re-arranged. To those of us with presbyopia, the smaller print may be a handicap but the final product is worth this minor inconvenience.

T. Scratcherd is Professor in the Department of Physiology, University of Sheffield, Sheffield S102TN, UK. 